\title{
Optimization based cost comparison between reinforced concrete and steel beams
}

\author{
I. Merta ${ }^{1}$, S. Kravanja ${ }^{2}$ \& U. Klanšek ${ }^{2}$ \\ ${ }^{1}$ Vienna University of Technology, \\ Institute for Building Construction and Technology, Austria \\ ${ }^{2}$ University of Maribor, Faculty of Civil Engineering, Slovenia
}

\begin{abstract}
This paper presents the optimization based cost comparison between reinforced concrete and doubly-symmetrical welded steel I beams. The task of the research was to define the spans at which each of two different considered structures would show its advantages. The optimization/comparison was performed for simply supported beams for spans between 5 and 30 meters and for a uniformly distributed variable imposed load of $5 \mathrm{kN} / \mathrm{m}$. The structural optimization was performed by the nonlinear programming (NLP) approach. The cost objective function was defined for the optimization and subjected to structural analysis constraints. The structures were designed in accordance with Eurocodes for both the ultimate and serviceability limit states. Beside the optimal self-manufacturing costs, the results also include the optimal masses for the different considered structures.
\end{abstract}

Keywords: structural optimization, non-linear programming, reinforced concrete beams, steel beams.

\section{Introduction}

The paper presents the optimization based cost comparison between reinforced concrete (RC) and doubly-symmetrical welded steel I beams. In order to determine the spans at which the individual structure shows its advantages, the cost comparison was carried out on the basis of the obtained optimal selfmanufacturing costs. The structural optimization was performed by the nonlinear programming (NLP) approach. 
In order to carry out the cost comparison, the optimization was performed for simply supported beams for six different spans from 5 to 30 meters with a 5 meter step. The considered beams were subjected to the self-weight and the uniformly distributed imposed load of $5.0 \mathrm{kN} / \mathrm{m}$. The combined actions on the structures were defined with respect to Eurocode 1 [1]. The concrete beams were designed in accordance with Eurocode 2 [2] and the steel I beams according to Eurocode 3 [3] in order to satisfy the requirements of both the ultimate and the serviceability limit states.

\section{Reinforced concrete beam}

Design/dimensioning of the RC beam was performed in accordance with Eurocode 2 for the conditions of both the ultimate and serviceability limit states. When the ultimate limit state of the RC beam was considered, the structure was checked for the bending moment and for the vertical shear force.

The ultimate strength design of the RC sections under the bending moment is defined by the non-linear constitutive laws of concrete and steel. The actual stress-strain diagram of concrete is replaced with a simplified equivalent rectangular stress-strain diagram. The maximum normal stress is limited to $0.85 f_{c d}$, where $f_{c d}$ is the design strength of the concrete under the compression (Fig. 1a). The ultimate compressive strain in the concrete $\varepsilon_{c u}$ is taken as $0.35 \%$. The tensile strength of the concrete is neglected.

A bi-linear design stress-strain law with the horizontal top branch was considered for the reinforcing steel as shown in Fig. 1b. The maximum normal stress is limited to $f_{y d}$ representing the design yield stress of the reinforcement; equal at tension and compression. No limit to the maximum strain is defined. The reinforcing steel behaves elastically until the maximum design stress $f_{y d}$ is reached corresponding to the maximum elastic strain $\varepsilon_{y d}$. $E_{s}$ denotes the elasticity modulus of steel.

a)

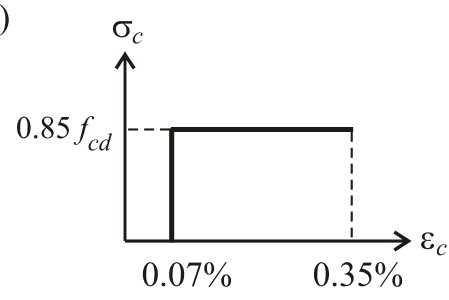

b)

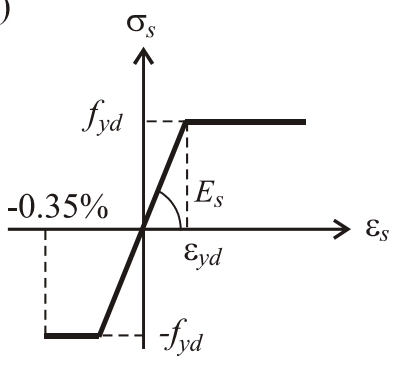

Figure 1: $\quad$ Design stress-strain diagrams of (a) concrete and (b) steel.

The ultimate flexural strength of a RC member is reached when the strain in the extreme compression fiber reaches the assumed maximum strain. Due to the concrete crushing at $0.35 \%$ the steel rupture under compression is limited to $0.35 \%$. 


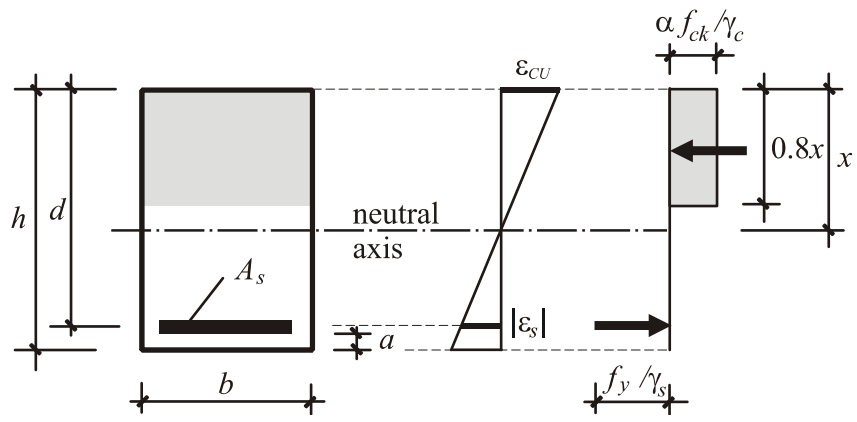

Figure 2: $\quad$ Cross-section of RC beam with strain and stress distribution.

The stresses, strains and the resulting load on the cross section are represented in Fig. 2, where the hatched area indicates the section's compression zone. The $0.07 \%$ strained fiber is located at the distance of $0.8 x$ from the fiber of maximum strain, where $x$ is the distance between the neutral axis and the section's top fiber.

Considering the serviceability limit state, the vertical deflection was calculated by the elastic method, considering the effective second moment of cross-sectional area and the effects of creep and shrinkage of the concrete. The deflection was limited under the maximum value of span/250. In addition, the minimal cross section of the tension reinforcement, necessary to control the crack widths, was calculated.

\section{Steel beam}

The doubly-symmetrical welded steel I beam is designed in accordance with Eurocode 3 for the conditions of both the ultimate limit and the serviceability limit states. When the ultimate limit states are considered, the steel I beam is checked for a required resistance of the cross-section to the bending moment, to shear, to the local buckling, to the shear buckling (for steel I beam without transverse stiffeners) and to the lateral-torsion buckling. The ultimate moment capacity is calculated by the elastic method.

When the serviceability limit state is checked, the vertical deflections of the beam are calculated by the elastic method. The deflections $\delta_{2}$, resulting from the variable imposed load, and the total deflections $\delta_{\max }$, resulting from the overall load, are defined to be calculated under the limited maximum values: span/300 and span/250, respectively.

\section{The optimization}

The non-linear continuous optimization problem can be formulated as:

$$
\begin{aligned}
& \text { Min } z=f(\boldsymbol{x}) \\
& \text { subjected to: } \boldsymbol{h}(\boldsymbol{x})=\mathbf{0} \\
& \boldsymbol{g}(\boldsymbol{x}) \leq \mathbf{0} \\
& \boldsymbol{x} \in \boldsymbol{X}=\left\{\begin{array}{c}
\left.\boldsymbol{x} \mid \boldsymbol{x} \in \boldsymbol{R}^{n}, \boldsymbol{x}^{L} \leq \boldsymbol{x} \leq \boldsymbol{x}^{U}\right\}
\end{array}\right.
\end{aligned}
$$


where $\boldsymbol{x}$ is a vector of continuous variables, defined within the compact set $\boldsymbol{X}$. Functions $f(\boldsymbol{x}), \boldsymbol{h}(\boldsymbol{x})$ and $\boldsymbol{g}(\boldsymbol{x})$ are nonlinear functions involved in the objective function $z$, equality and inequality constraints, respectively. All functions $f(x)$, $\boldsymbol{h}(\boldsymbol{x})$ and $\boldsymbol{g}(\boldsymbol{x})$ must be continuous and differentiable.

With regard to the above NLP problem formulation, two different optimization models for the RC and steel I beams were developed. The models include the constants (input data), continuous variables, structural analysis constraints and structure's cost objective function.

The optimization model constants include the span, variable imposed load, several material parameters, costs, partial safety factors, etc. Defined input data remain fixed for the individual optimization.

In the context of optimization, the variables denote entities whose values are generally unknown until after a model has been solved. The optimization model variables represent the parameters of structure e.g. dimensions, cross-section characteristics, materials, design loads, internal forces, deflections, economic parameters, etc. The optimal values of the considered variables are obtained when the minimal self-manufacturing costs of the structure are reached.

The optimization model (in)equality constraints and the bounds of the variables represent a rigorous system of the design, loading, stress, deflections and stability functions. While the majority of the design constraints are determined from the Eurocodes (the ultimate and serviceability limit states), constraints of the design forces and the deflections are derived from the structural analysis.

For the purpose of better illustration, the fundamental (in)equality constraints and the objective function of the optimization model of the RC beam are presented. Within the scope of structural design, the (in)equality constraints were formed as a constraint of ultimate and serviceability limit states for the RC beam.

Resistance to bending moment of the RC cross section:

$$
\begin{gathered}
M_{S d} \leq M_{R d} \\
M_{R d}=\frac{\alpha \cdot f_{c k}}{\gamma_{c}} \cdot 0.48 \cdot b \cdot x^{2}+\frac{f_{y}}{\gamma_{s}} \cdot A_{s} \cdot(d-x)
\end{gathered}
$$

where $M_{S d}$ is the design bending moment, $M_{R d}$ is the design moment resistance, $f_{y}$ is the yield strength of reinforcement, $f_{c k}$ is the characteristic cylinder strength of concrete, $\alpha$ is the coefficient which takes account of the long-term effects on the compressive strength of concrete and of the unfavorable effects resulting from the way in which the load is applied, $\gamma_{c}, \gamma_{a}$ are the safety coefficients for concrete and structural steel, respectively. For other denotations, see Fig. 2.

Resistance to shear force of a RC cross section:

$$
V_{S d} \leq V_{R d, c}+V_{R d, s}
$$

where $V_{S d}$ is the design shear force, $V_{R d, c}$ the design shear resistance of the member without shear reinforcement and $V_{R d, s}$ the design shear resistance of vertical shear reinforcement.

$$
V_{R d, c}=\left[C_{R d, c} \cdot k \cdot\left(100 \cdot \rho_{l} \cdot f_{c k}\right)^{1 / 3}+k_{1} \cdot \frac{N_{E d}}{A_{c}}\right] \cdot b_{w} \cdot d
$$




$$
V_{R d, s}=\frac{A_{s w}}{s} \cdot z \cdot \frac{f_{y w}}{\gamma_{s}} \cdot \cot \theta
$$

The design shear force must be smaller than the maximum shear force that can be carried without crushing of the notional concrete compressive struts:

$$
\begin{gathered}
V_{S d} \leq V_{R d, \max } \\
V_{R d, \max }=\alpha_{c w} \cdot b_{w} \cdot z \cdot v_{1} \cdot \frac{f_{c k}}{\gamma_{c}}
\end{gathered}
$$

In eqs. (4), (5) and (7) $b_{w}$ is the section's minimum width over the effective depth (for rectangular section $b_{w}=b$ ), $N_{E d}$ is the longitudinal force in section due to loading or prestressing, $A_{c}$ is the concrete gross section, $A_{s w}$ is the shear reinforcement's cross-sectional area (two times the area of the bar), $s$ is the spacing and $f_{y w}$ the shear reinforcement's yield strength, $z$ is the internal lever arm and may normally be taken as $0.9 d$. $\theta$ is the inclination angle of cracks (or concrete compression strut) and is generally taken to be $45^{\circ}$. $\rho_{l}=A_{s l} /\left(b_{w} \cdot d\right) \leq 0.02$ is the longitudinal reinforcement ratio with $A_{s l}$ denoting the area of tension reinforcement extending not less than $d+l_{b d}$ beyond the section considered, $l_{b d}$ is the anchorage length. The coefficients $C_{R d, c}, k, k_{1}$, $\alpha_{c w}$ and $v_{1}$ are defined as: $C_{R d, c}=0.18 / \gamma_{c} ; k=1+\sqrt{200 / d} \leq 2.0 ; k_{1}=0.15$; $\alpha_{c w}=1.0$ for $N_{E d}=0$ and $v_{1}=0.6$ for $f_{c k} \leq 60 \mathrm{~N} / \mathrm{mm}^{2}$.

The additional (in)equality constraints of the optimization model defined by Eurocode 2 are the following ones:

- for an element of the structure to be considered as a beam, its span should be not less than twice the overall section's depth: $l \geq 2 \cdot h$,

- the ductility constrain where no redistribution of the moments has been carried out: $x / d=0.45$ (for $\mathrm{C} 12 / 15$ to $\mathrm{C} 35 / 45$ ),

- the minimal amount of the longitudinal tensile reinforcement should be: $A_{s} \geq 0.0015 \cdot b \cdot d$ and $A_{s} \geq 0.6 \cdot b \cdot d \cdot f_{y k}$,

- the maximal cross-sectional area of the tension (and compression reinforcement) should be: $A_{s} \leq 0.04 \cdot b \cdot h$.

When the serviceability limit state is checked, the deflection of the structure is kept under the maximum allowable deflection of span/250 as well as the minimal cross section of the tension reinforcement necessary to control the crack widths is calculated.

The cost objective function of the objective variable COST represents the self-manufacturing costs of beams. The material used is standard structural steel S 355 and concrete C 25/30. The material costs are given in Table 1. The proposed cost objective function of the $\mathrm{RC}$ beam includes the material costs of concrete, longitudinal tension reinforcement and shear reinforcement. The cost function of the steel I beam comprises the material costs of the structural steel and the fire resistant-painting. 


$$
\begin{gathered}
\text { RC beam } \min : \operatorname{COST}=C_{c} \cdot V_{c}+C_{r} \cdot \rho_{s} \cdot V_{s, l}+C_{r} \cdot \rho_{s} \cdot V_{s w} \\
\text { Steel beam } \min : \operatorname{COST}=C_{s} \cdot \rho_{s} \cdot V_{s}+C_{f, a c} \cdot A_{f, a c}
\end{gathered}
$$

where COST denotes the self-manufacturing costs of the beams; $C_{c}, C_{r}$ and $C_{f, a c}$ are material costs defined in Table $1 ; V_{c}, V_{s, l}, V_{s w}$ and $V_{s}$ represent the volumes of concrete, longitudinal reinforcement, shear reinforcement and structural steel respectively; $\rho_{s}$ is the unit mass of steel and $A_{f, a c}$ is the exposed area of steel parts.

The NLP cost optimization models were developed by using the high level language GAMS (General Algebraic Modelling System) [4]. CONOPT (Generalized reduced-gradient method) was used for the optimization (Drud [5]).

\section{Comparison of the obtained results}

The optimization was performed for both RC and steel I beams for spans from 5 to 30 meters and for variable imposed load of $5 \mathrm{kN} / \mathrm{m}$. As the self-weight of the structure depends on its optimal cross-section, it was automatically calculated within the individual optimization process. The masses of the beams were thus calculated within each individual optimization process.

The cost comparison of two different types of beams shows that for spans up to $12 \mathrm{~m}$ the RC beams are cheaper than the steel I beams. However, for the spans longer than $12 \mathrm{~m}$, the steel I beams are a more economical solution (Figs. 3 and 4). Fig. 5 shows the normalized costs of the beams, i.e. the ratio of the prices

Table 1: $\quad$ Material costs.

\begin{tabular}{|l|l|c|c|}
\hline$C_{c}$ & Material and erection costs for concrete C 25/30 & 90,0 & $\mathrm{EUR} / \mathrm{m}^{3}$ \\
\hline$C_{s}$ & Material costs for structural steel S 355 & 1,0 & $\mathrm{EUR} / \mathrm{kg}$ \\
\hline$C_{r}$ & Material and erection costs for reinforcing steel S 355 & 0,9 & $\mathrm{EUR} / \mathrm{kg}$ \\
\hline$C_{f, a c}$ & Fire protection and anti-corrosion painting costs & 25,0 & $\mathrm{EUR} / \mathrm{m}^{2}$ \\
\hline
\end{tabular}

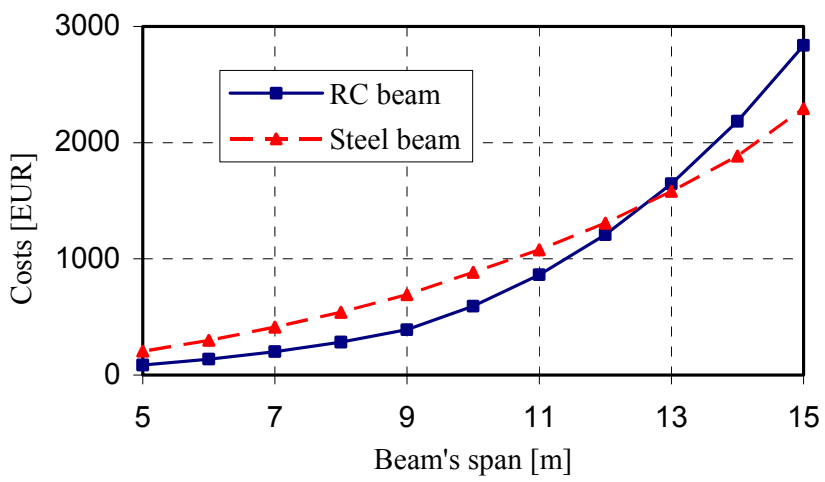

Figure 3: $\quad$ Self-manufacturing cost of beams (for spans 5-15 m). 
between the steel I beam and the RC beam. The comparison of the obtained masses for the two structures is shown in Fig. 6. As expected, the RC beams are considerably heavier than the steel I beams for all spans.

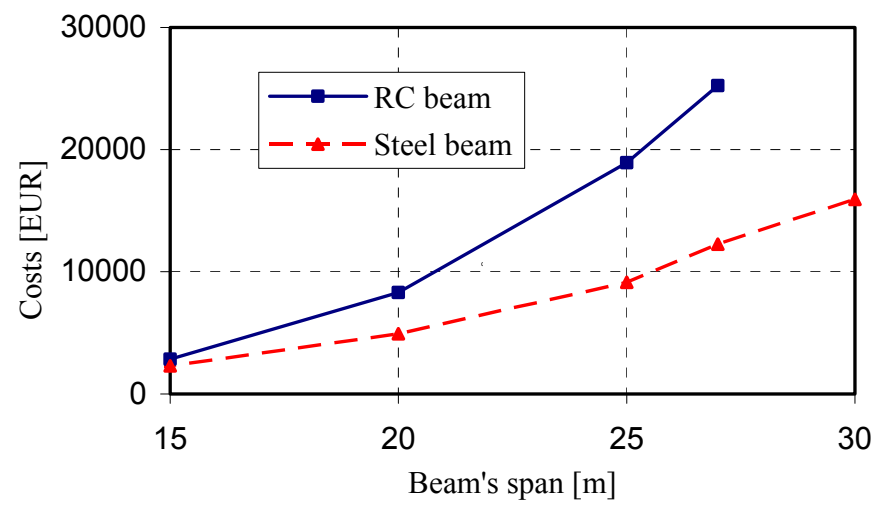

Figure 4: Self-manufacturing cost of beams (for spans $15-30 \mathrm{~m}$ ).

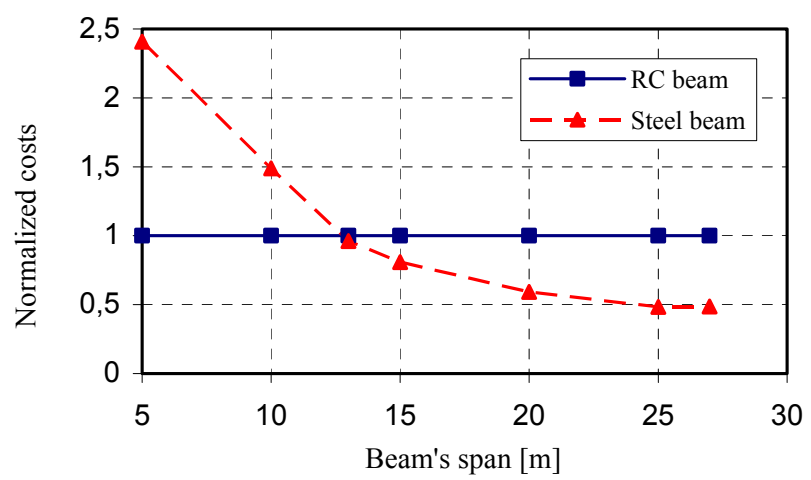

Figure 5: Normalized cost of beams.

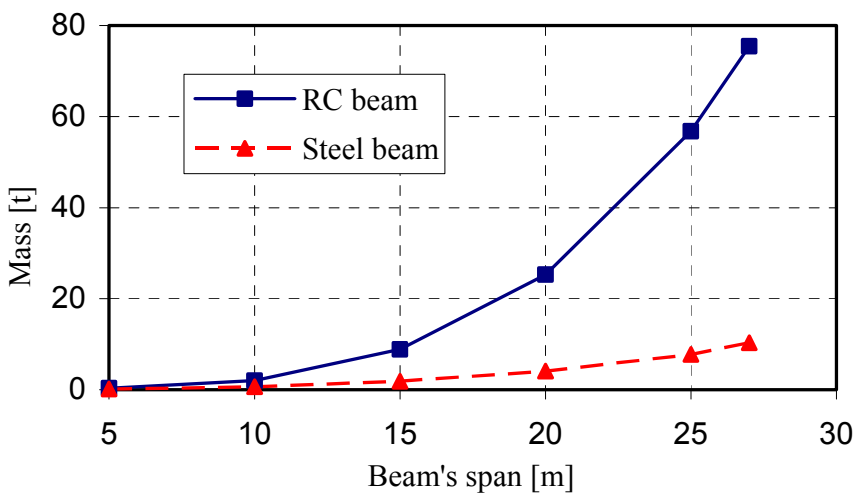

Figure 6: Mass of beams. 


\section{Conclusions}

In the presented research, a cost comparison between the reinforced concrete (RC) beams of a rectangular cross-section and the steel beams of an I section was carried out on the basis of the obtained results of the NLP structural optimization. The optimization and the comparison between the beams was performed for the spans from 5 to $30 \mathrm{~m}$ and for the variable imposed load of $5 \mathrm{kN} / \mathrm{m}$.

The comparison of the self-manufacturing costs shows that the $\mathrm{RC}$ beams are cheaper than the steel I beams for the spans up to $12 \mathrm{~m}$. For the spans beyond 12 $\mathrm{m}$, the steel I beams are a more economical solution. Finally, the comparison of masses has showed that for all spans the RC beams are essentially heavier constructional elements.

\section{References}

[1] Eurocode 1, Actions on structures, European Committee for Standardization, Brussels, 2004.

[2] Eurocode 2, Design of concrete structures, European Committee for Standardization, Brussels, 2004.

[3] Eurocode 3, Design of steel structures, European Committee for Standardization, Brussels, 2005.

[4] Brooke, A., Kendrick, D. and Meeraus, A., GAMS - A User's Guide. Scientific Press, Redwood City, CA, 1988.

[5] Drud, A.S., CONOPT - A Large-Scale GRG Code, ORSA Journal on Computing, Vol. 6, No. 2, pp. 207-216, 1994. 